was expelled immediately without delay. ${ }^{9}$ However, use of air flushing must be controlled as inappropriate pressure may result in spraying of the material. However, single centre study and use of needles of different gauge size are limitations of the current study. It also would be interesting to note differences, if any, between the diagnostic yield of first pass and subsequent passes as the increasing number of passes makes the needle deformed and blunted.

\section{Randomized Trial Comparing Fanning with Standard Technique for Endoscopic Ultrasound-guided Fine- needle Aspiration of Solid Pancreatic Mass Lesions}

\author{
Bang JY, Magee SH, Ramesh J, Trevino JM, \\ Varadarajulu S \\ Endoscopy 2013 early online; doi 10.1055/s-0032-1326268
}

Endoscopic ultrasound guided fine needle aspiration (EUS-FNA) is a preferred diagnostic modality for evaluation of solid pancreatic lesions as it is safe and has high diagnostic accuracy. ${ }^{1,2}$ As mentioned earlier, the diagnostic yield of EUSFNA depends on number of variables that include the size of the lesion, experience of the endosonologist, the guage of the needle, the number of passes, presence of onsite cytopathologist, methods used for slide preparation and the location of the mass in the pancreas. ${ }^{3,4}$ Certain technical manoeuvres like doing sampling from the lesion's edge and the use of "fanning" have been described to increase the diagnostic yield. However, these techniques have not been compared with the standard FNA techniques. In the current study, the authors conducted a randomized trial comparing the fanning technique with the standard approach where only a single area within the mass was targeted and tried to determine if fanning could enhance diagnostic accuracy and whether the number of passes needed to achieve a diagnosis could be reduced.

The trial was done by using a single needle (25 Gauge for head and uncinate and 22 Gauge for lesions of body and tail; Expect; Boston Scientific Corp., Natick, Massachusetts, USA) and a single expert endosonologist did all the procedures. In the standard technique the tip of the needle was positioned at a single location and moved 16 times to target the periphery of the lesion. In the fanning technique the needle was positioned at four different areas within the mass and moved back and forth four times. On site pathologist, blinded to the EUS-FNA technique, immediately interpreted the yield thereby allowing for assessment of number of passes. A maximum number of three passes were allowed per technique and if required the patient was crossed over to the second technique. Of the 54 patients eventually randomised, 26 were randomised to standard EUS-FNA and 28 were randomised to the fanning technique. Although the two groups were comparable in tumour characteristics, tumour location, or the route of FNA but the fanning group had lesions with a smaller size than the standardized group ( $30 \mathrm{~mm}$ versus $40 \mathrm{~mm} ; p=0.009$ ). The total number of passes needed to achieve a diagnosis was significantly lesser in the fanning group $(p=0.02)$. Also a higher proportion of patients achieved a diagnosis on first pass in the fanning technique ( $85.7 \%$ vs. $57.7 \% ; p=0.02$, respectively). The diagnostic accuracy was comparable for the two groups (Fanning 96.4\% and Standard $76.9 \% ; p=0.05$ ). A higher number of patients in the standard technique needed to be crossed over to the fanning technique (six versus one). No procedural complications or needle dysfunction was encountered in either group. The authors concluded that the fanning technique of FNA is superior to the standard approach as fewer passes are required to establish a diagnosis.

\section{Commentary}

This is a well conducted randomized study that has established the superiority of the fanning technique for EUS FNA. One earlier report had also indicted that EUS-FNA from the multiple sites might increase the yield form pancreatic masses. ${ }^{10}$ However, it would be interesting to know the sub-analysis of small lesions as fanning may be difficult in very small lesions. The current study included only solid lesions of the pancreas and the results if the fanning technique needs to be addressed for other lesions and results from other centres with varying underlying lesions are awaited before finally it can be said that fanning technique is the best. Summing up the two studies discussed in this section, it appears the EUS guided FNA being done with suction and using fanning technique with the sample being expressed using air suction may be the preferred method of doing EUS FNA for solid pancreatic lesions.

\section{References}

1. Hewitt MJ, McPhail MJ, Possamai L, Dhar A, Vlavianos P, Monahan KJ. EUS-guided FNA for diagnosis of solid pancreatic neoplasms: a meta-analysis. Gastrointest Endosc 2012;75:319-31.

2. Rana SS, Bhasin DK, Srinivasan R, Sampath S, Mittal BR, Singh K. Distinctive endoscopic ultrasound features of isolated pancreatic tuberculosis and requirements for biliary stenting. Clin Gastroenterol Hepatol 2012; 10:323-325.

3. Siddiqui AA, Brown LJ, Hong SK, Draganova-Tacheva RA, Korenblit J, Loren DE. Relationship of pancreatic mass size and diagnostic yield of endoscopic ultrasound-guided fine needle aspiration. Dig Dis Sci 2011; 56:3370-5.

4. Savides TJ. Tricks for improving EUS-FNA accuracy and maximizing cellular yield. Gastrointest Endosc 2009;69: S130-3.

5. Thomson HD. Thin needle aspiration biopsy. Acta Cytol 1982; 26:262-3. 
6. Puri R, Vilmann P, Saftoiu A, Skov BG, Linnemann D, Hassan $\mathrm{H}$, et al. Randomized controlled trial of endoscopic ultrasound-guided fine-needle sampling with or without suction for better cytological diagnosis. Scand J Gastroenterol 2009;44:499-504.

7. Wallace MB, Kennedy T, Durkalski V, Eloubeidi MA, Etamad R, Matsuda K, et al. Randomized controlled trial of EUS-guided fine needle aspiration techniques for the detection of malignant lymphadenopathy. Gastrointest Endosc 2001;54:441-7.

8. Larghi A, Noffsinger A, Dye CE, Hart J, Waxman I. EUSguided fine needle tissue acquisition by using high negative pressure suction for the evaluation of solid masses: a pilot study. Gastrointest Endosc 2005;62:768-74

9. Sahai AV, Paquin SC, Gariepy G. A prospective comparison of endoscopic ultrasound-guided fine needle aspiration results obtained in the same lesion, with and without the needle stylet. Endoscopy 2010;42:900-3

10. Wyse JM, Paquin SC, Joseph L, Sahai A. EUS-FNA without the stylet: the yield is comparable to that with the stylet and sampling of multiple sites during the same pass may improve sample quality and yield. Gastrointest Endosc 2009;69: AB330-AB331.

Reprints requests and correspondence:

Dr. Surinder Singh Rana

Department of Gastroenterology, PGIMER, Chandigarh - 160012 , India Tel: +91-172-2749123

Fax: +91-172-2744401

drsurinderrana@yahoo.co.in

Source of support: Nil; Conflict of interest: none declared 